\title{
Determination of the Chemical Structure of the Iraqi Oil Shale and Its Hydrocarbon Forms
}

\author{
Atiya Al-Zuheri', Haider Rashad1, Ali A. Al Maliki', Hussain M. Hussain², Nadhir Al-Ansari ${ }^{3}$ \\ ${ }^{1}$ Ministry of Science and Technology, Baghdad, Iraq \\ ${ }^{2}$ Remote Sensing Center, University of Kufa, Najaf, Iraq \\ ${ }^{3}$ Lulea University of Technology, Lulea, Sweden \\ Email: atiya.alzuheri@unisa.edu.au,haider.rashad@gmail.com, aligeo1969@gmail.com, \\ hussainm.alshimmary@uokufa.edu.iq,nadhir.alansari@ltu.se
}

How to cite this paper: Al-Zuheri, A. Rashad, H., Al Maliki, A.A., Hussain, H.M. and Al-Ansari, N. (2018) Determination of the Chemical Structure of the Iraqi Oil Shale and Its Hydrocarbon Forms. Engineering, 10, 7-20.

https://doi.org/10.4236/eng.2018.101002

Received: January 4, 2018

Accepted: January 27, 2018

Published: January 30, 2018

Copyright (c) 2018 by authors and Scientific Research Publishing Inc. This work is licensed under the Creative Commons Attribution International License (CC BY 4.0).

http://creativecommons.org/licenses/by/4.0/

\begin{abstract}
The global impact of shale oil has revolutionized the world's energy markets, resulting in significantly lower oil prices, higher global gross domestic product, changing geopolitics and shifted business models for oil and gas companies. Further and developed research initiative is required to fill critical gaps in knowledge at the interface of shale oil development along with environmental protection, so countries can prepare better for its energy future. This paper explores the characterization of Iraqi originated oil shale using various analytical techniques, such as mass spectrometry (MS), infrared spectroscopy (IR), and Gas Chromatography Mass Spectrography (GC/MS). Based upon analytical results, it is found that the majority of chemical structure is in aliphatic hydrocarbon forms.
\end{abstract}

\section{Keywords}

Oil Shale, MS, IR, GC/MS, Characterization

\section{Introduction}

A few years ago, the search for alternative sources of raw materials has concentrated on oil shale deposits. As the exploitation of these raw materials is still extremely complex and expensive, analysis of oil shale samples is therefore extremely important in identifying the deposit's potential in advance to facilitate in optimizing mining methods [1]. "Oil Shale" is a term used to identify rock types found in northern Iraq and currently used within the construction industry; in particular granite tile fabrication. Figure 1 shows a sample from this type of tiles including the type of oil shale rock which has darker colour. The rocks are solid 


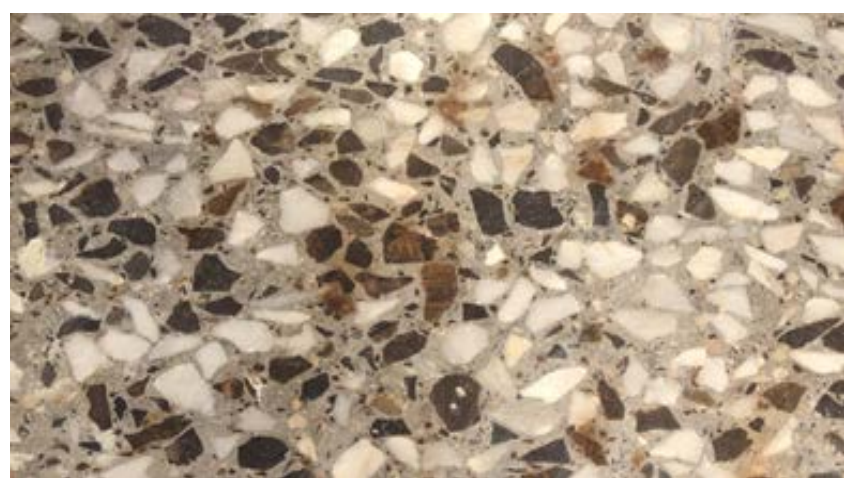

Figure 1. The use of Iraqi oil shale within the tiling industry. The darker elements represent the oil shale rock.

with alternating layers of carbonate and organic matter. In Iraq, nowadays, there is no viable literature found regarding these rock types. Part of the reason for the lack of research work relative to "oil shale" is due to cheap production of crude oil in Iraq. The proven massive oil reserves in the country are considered to be the world's fifth-largest with 140 billion barrels [2]. Oil produced from shale formations costs $\$ 50$ to $\$ 100$ for a barrel to be produced, compared with $\$ 10$ to \$25 for a barrel for conventional supplies from the Middle East and North Africa. Table 1 summarizes the results of some of Iraq's oil technical service contracts signed by the Iraqi government with some big oil companies [3]. As the table shows, the cost of Iraqi oil extraction is relatively low. Besides, geologists and consultants have estimated that relatively unexplored territory in the western and southern deserts may contain estimated additional 45 to 100 billion barrels (bbls) of recoverable oil.

However, the production of shale oil, from oil shale, is one of the energy generation alternatives available in the world today. Oil shale is a sedimentary rock containing a complex organic substance called kerogen and its conversion to oil is considered a valuable source of energy. Therefore, an important indicator is the kerogen content which could be relative in predicting accurately the oil yield within the shale. This research focuses on the characterization of this type of oil shale (Figure 2) found in Iraq and some other countries in the Middle East, such as Jordan and Palestine, using different techniques as follows, solvent extraction (SE), infrared radiation spectroscopy (IR), and gas and mass chromatography (GC/MS).

\section{Methodology}

\subsection{Samples Preparation}

Oil shale samples were obtained from one factory in Baghdad, specializing in the fabrication of tiles. The raw rock material collected from a supplier in Said Sadiq Province, Al Sulaymaniah Governorate, and northern Iraq. All samples were from one deposit. Each shale sample was crushed and mixed thoroughly and then about $10 \mathrm{~g}$ was separated and ground to a fine powder $(50 \mu \mathrm{m})$. Later, the 
Table 1. Some of Iraq's oil technical service contract results [3].

\begin{tabular}{cccc}
\hline Field/block & Company & Home country & Company type \\
\hline Badra & Gazprom & Russia & State \\
Badra & Petronas & Malaysia & State \\
Badra & KOGAS & Korea & State \\
Badra & TPAO & Turkey & State \\
Garraf & Petronas & Malaysia & State \\
Garraf & JAPEX & Japan & Public \\
Halfaya & CNPC & China & State \\
Halfaya & Petronas & Malaysia & State \\
Halfaya & Total & France & Public \\
Majnoon & Shell & Netherlands & Public \\
Majnoon & Petronas & Malaysia & State \\
Missan G. & CNOOC & China & State \\
Missan G. & TPAO & Turkey & State \\
Najmah & Sonangol & Angola & State \\
Qayara & Sonangol & Angola & State \\
Rumaila & BP & UK & Public \\
Rumaila & CNPC & China & State \\
W.Qurna & Exxon & US & Public \\
Zubair & ENI & Italy & Public \\
Zubair & Occidental & Us & State \\
Zubair & KOGAS & & \\
\hline & & Korea & \\
\hline
\end{tabular}

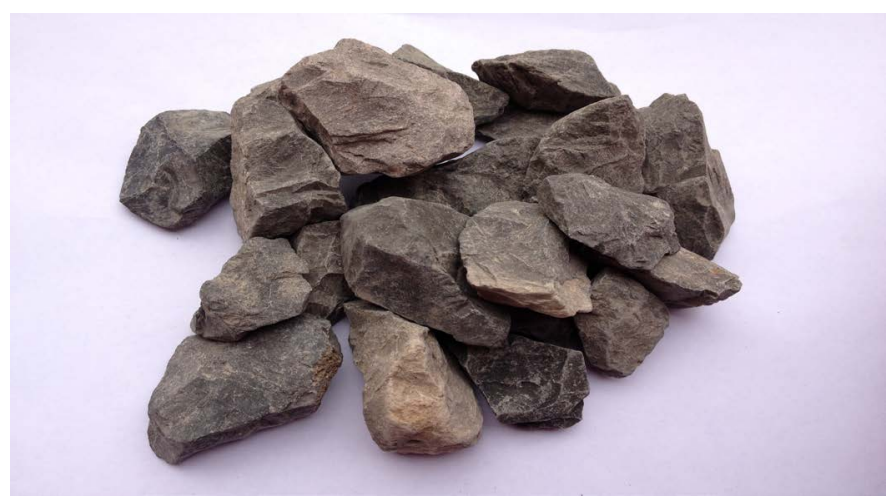

Figure 2. Iraqi oil shale rock used in this paper.

ground oil shale samples were utilized for analysis.

\subsection{Analysis Tests of Chemical Structure}

1) MS: mass spectrometry is an analytical tool that uses mass to charge ratios to determine molecular weights of the chemical structure compounds in oil shale samples. This technique has been utilized previously for several studies in pyrolysis of oil shale, tar sands, and coal [4]. Full details of this technique have been 
published somewhere else.

2) IR: infrared radiation spectroscopy is well-established as a useful technique for the identifying chemical characteristics of coal and kerogen [5]. The spectra were measured at $1 \mathrm{~cm}^{-1}$ resolution and collected in the $400-4000 \mathrm{~cm}^{-1}$ wave number range.

3) GC/MS: In order to more fully characterize the compounds, present in the Iraqi oil shale, since MS analysis gives a compound classification only, the gas chromatograph coupled with a mass spectrometer using electron impact ionization, is used for analyzing and separating the samples [6]. The GC was equipped with an automatic programmable-temperature system and a capillary column ( $30 \mathrm{~m} \times 0.25 \mathrm{~mm}$ I.D.). Helium is used as the carrier gas.

\section{Results and Discussion}

\subsection{MS Analysis}

Solvent extraction (SE) for the shale samples was undertaken using two different solvents; dichloromethane and ethanol. There were no results from the extracts with ethanol. Mass Spectrometry (MS) analysis, for the extraction performed when using dichloromethane as a solvent, indicated that there were absorptions of bands at the retention time (tR) $(8.5,8.88,8.87,13.15,14.96$ minutes). This result confirmed the extraction and the existence of other compounds, too.

\subsection{IR Analysis}

Extracted oil shale sub samples were put in a diffuse reflectance cup $(10 \mathrm{~mm}$ diameter, $3.3 \mathrm{~mm}$ depth) in which the packing density was ensured by applying a constant mass ( of $30 \mathrm{~g}$ ) on the top surface of each sample. The IR spectrometer was then used for analyses. The spectra indicated $\mathrm{CH}$-aliphatic at bands with $3052-3852 \mathrm{~cm}^{-1}$ wave number. Also, there were groups of C-S and S-H compounds at bands with $900-1124 \mathrm{~cm}^{-1}$ wave number. Finally, amide O-C- $\mathrm{NH}_{2}$ appeared within the band showing a $1724 \mathrm{~cm}^{-1}$ wave number. The curves of different values of percentage transmittance $(\% \mathrm{~T})$ versus the frequency of vibration, with using dichloromethane as solvent, are presented in Figure 3 \& Figure 4 respectively.

\subsection{IR for the Whole Rock Analysis}

IR analysis for the whole rock showed characteristic bands at $2876-2980 \mathrm{~cm}^{-1}$. The bands were related to $\mathrm{CH}$-aliphatic. Also, Amide $\mathrm{O}-\mathrm{C}-\mathrm{NH}_{2}$, appeared with the band, had a wave number of $796 \mathrm{~cm}^{-1}$. In addition, further spectra IR with band peaks at $876 \mathrm{~cm}^{-1}$ to $1036 \mathrm{~cm}^{-1}$ showed some evidence for the presence of $\mathrm{S}-\mathrm{H}$ and C-S groups. The IR analysis (Figure 5) gives evidence of a complex chemical composition of the sample in forms of different types of groups deriving from the decomposition of various groups of the molecule. In the next section, what kinds of groups are actually existed in the oil shale sample is introduced. The figure profile shows numerous events. In fact, the number of peaks 


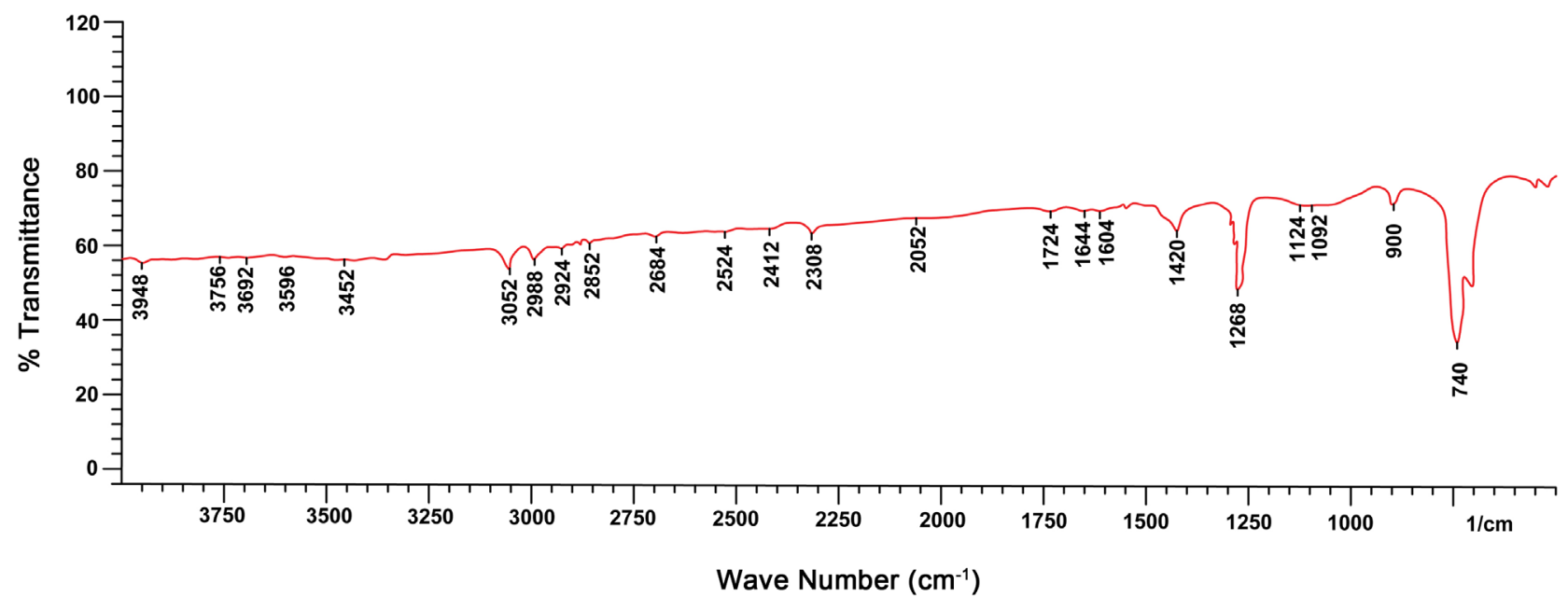

Figure 3. Curve of percentage transmittance (\%T) (ranges from 55\%-65\%) versus frequency of vibration (in wave numbers) for scanning of the extracted oil samples with using dichloromethane as solvent.

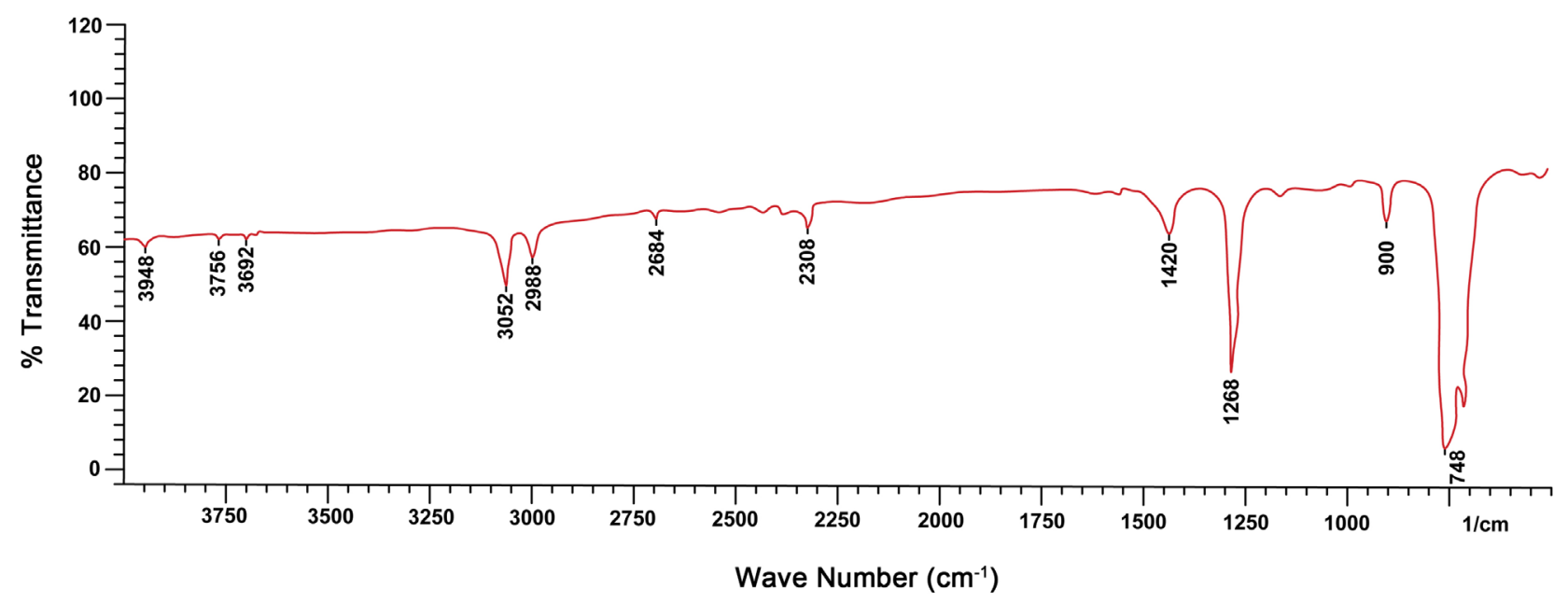

Figure 4. Curve of percentage transmittance (\%T) (ranges from 65\% - 75\%) versus Frequency of vibration (in wave numbers) for scanning of the extracted oil samples with using dichloromethane as solvent.

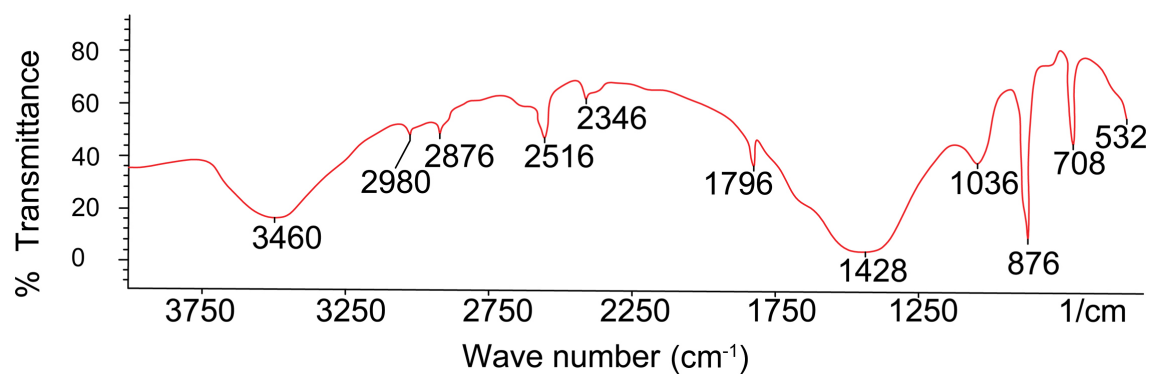

Figure 5. The IR spectra analysis of the whole oil shale rock provided identifiable peaks for the carbon bonds (near $3000 \mathrm{~cm}^{-1}$ ), and also the oxygen carbon group (near 800 $\left.\mathrm{cm}^{-1}\right)$.

in the chromatogram is more than number of peaks of the extracted oil samples using dichloromethane. 


\subsection{GC/MS Analysis}

The GC separates the compounds from each other, while the mass spectrometer helps to identify them based on their fragmentation pattern. Here, methanol was used and thus considered the best solvent for extraction purposes when looking for information on the chemical structure of the sample. Following? extraction, a sample extract was filtered for analysis by GC/MS system. The compounds of hydrocarbon forms were detected in a mass spectrometer (MS) interfaced to gas chromatograph (GC), and they are summarized in Table 2. These results are consistent with those of the MS analysis.

The elemental composition of the extracted oil was found to be $\mathrm{C}, \mathrm{H}$, and $\mathrm{N}$. Full details of the GC/MS analysis are presented in Appendix.

\section{Summary of Results}

Several analytical techniques were employed to characterize the chemical composition of the oil shale. When considered alone, each technique has its own advantage, but it was unable to provide the whole picture for oil shale [7]. The chemical composition of the oil shale available in Iraq was found to be of a series of hydrocarbon forms. Hydrocarbon type analysis indicated that mono and di-cycloparaffins were the next most abundant constituents after the paraffin series.

The organic carbon content was a good indicator for the quality of organic matter in the oil shale. Depending on the previous result, it was observed that the Iraqi Oil shale contained similar chemical composition of Egyptian oil shale, which indicated in the research of Al-Alla RA, Nassef E [8].

\section{Recommendation for Further Research}

Chemically, oil shale consists of carbon, hydrogen, oxygen, nitrogen, and sulphur and all of these components are existed in Iraqi oil shale. The existence of these components, which has been noted, may considerably influence the results of structural investigations as reported in the literature. Further characterization of the oil shale by distinguishing between the aliphatic and aromatic hydrocarbons is needed. Also, since the challenges of economically developing unconventional shale deposits vary with the characteristics of the deposit, extraction costs,

Table 2. Hydrocarbon forms in the oil shale samples.

\begin{tabular}{cccc}
\hline No. & Compound Name & Formula & Molecular weight \\
\hline 1 & Propanesulfonylacetonitrile & $\mathrm{C}_{5} \mathrm{H}_{9} \mathrm{NO}_{2} \mathrm{~S}$ & 147.195 \\
2 & Butyl Isocyanide & $\mathrm{CH}_{3}\left(\mathrm{CH}_{2}\right)_{3} \mathrm{NC}$ & 83.13 \\
3 & O-Allylhydroxylamine & $\mathrm{C}_{3} \mathrm{H}_{7} \mathrm{NO}$ & 73.11 \\
5 & N-Hexadecanoic Acid & $\mathrm{C}_{16} \mathrm{H}_{32} \mathrm{O}_{2}$ & 256.4241 \\
6 & 2-Propenoic Acid, Ethenyl Ester & $\mathrm{C}_{5} \mathrm{H}_{8} \mathrm{O}_{2}$ & 100.1158 \\
7 & Z-10-Pentadecen-1-o1 & $\mathrm{C}_{15} \mathrm{H}_{30} \mathrm{O}$ & 226 \\
8 & 1,1-Diisobutoxy-Isobutane & $\mathrm{C}_{12} \mathrm{H}_{26} \mathrm{O}_{2}$ & 202.334 \\
\hline
\end{tabular}


topography, land uses, water resource availability and climate, some of these concerns can be better understood in the light of further research. Therefore, this highlights further demand for research in a number of relevant areas, including the following:

1) Confirming the proportions of the mixture of hydrocarbon compounds found in the Iraqi oil shale, that it is Kerogen and of which type it is: alpha or beta?

2) Evaluating the potential extracted oil yield.

3) Studying the economic feasibility of extracting Kerogen from this type of oil shale, taking into consideration the oil price which is around $\$ 100 /$ barrel as minimum.

4) Selecting the appropriate processing technology whilst considering the reduction in extraction costs per barrel, and reducing the carbon footprint relative to the extraction process.

\section{References}

[1] Batista, K.T. (1988) Shale Oil Industry. International Conference on Oil Shale and Shale Oil, Beijing.

[2] Administration, U.E.i. (2015) Country Analysis Brief: Iraq.

[3] Wells, P. (2009) Iraq's Technical Service Contracts-A Good Deal for Iraq? Middle East Economic Survey.

[4] Larter, S.R. and Horsfield, B. (1993) Determination of Structural Components of Kerogens by the Use of Analytical Pyrolysis Methods. Organic Geochemistry, 11, 271-287. https://doi.org/10.1007/978-1-4615-2890-6_13

[5] Rochdi, A. and Landais, P. (1991) Transmission Micro-Infrared Spectroscopy: An Efficient Tool for Microsample Characterization of Coal. Fuel, 70, 367-371. https://doi.org/10.1016/0016-2361(91)90124-S

[6] Ei Mon Han, Y.S. and Roser, B.P. (2014) Characterization of Kerogen Using Combined Pyrolysis-GC-MS and FT-IR in Weathered and Unweathered Coals and Coaly Shales from the Central Myanmar Basin. Research in Organic Geochemistry, 29, 49-59.

[7] Suresh Bhargava, F.A. and Subasinghe, N.D. (2005) Characterisation of Some Australian Oil Shale Using Thermal, X-Ray and IR Techniques. Fuel, 84, 707-715. https://doi.org/10.1016/j.fuel.2004.11.013

[8] Ramadan Abu Al-Alla, E.N. (2015) Extraction of Oil from Egyptian Oil Shale. Journal of Petroleum \& Environmental Biotechnology, 6. 


\section{Appendix}

$<$ Target $>>$

Line\#:1 R.Time:10.625(Scan\#:1036) MassPeaks:3 RawMode:Averaged 10.600-10.650(1033-1039)BasePeak:41.00(771) BG Mode:10.658(1040) Group 1 - Event 1

100

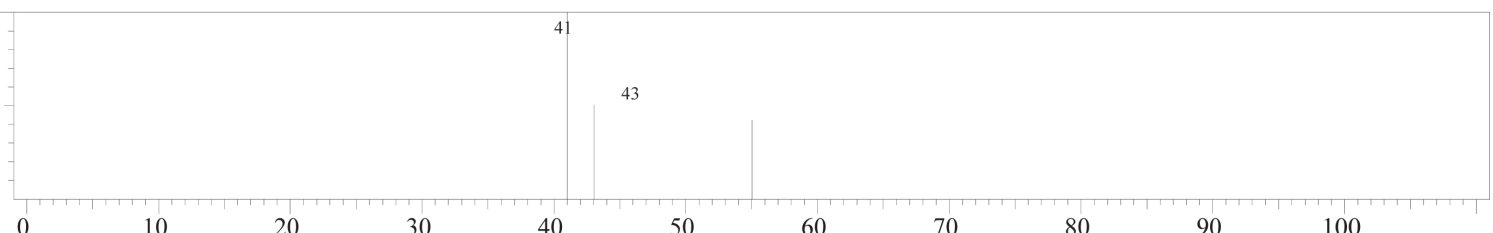

Hit\#:1 Entry:13866 Library:NIST08.LIB

SI:84 Formula:C5H9NO2S CAS:175137-61-8 MolWeight:147 RetIndex:1270

CompName:Propanesulfonylacetonitrile \$ (Propylsulfonyl)acetonitrile\# \$\$

100

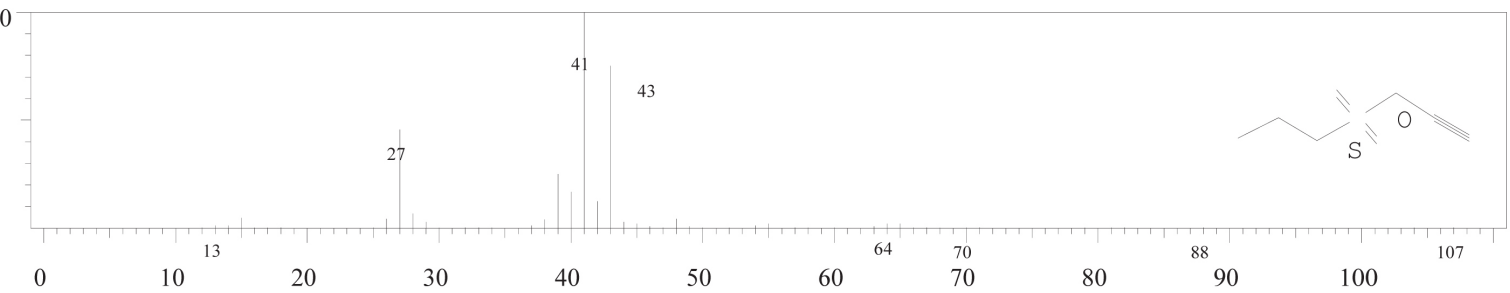

Hit\#:2 Entry:264 Library:NIST08.LIB

SI:83 Formula:C4H11B CAS:1113-22-0 MolWeight:70 RetIndex:0

CompName:Borane, ethyldimethyl-\$\$ Dimethylethylborane \$ B Borine, ethyldimethyl-\$ Ethyl(dimethyl)borane\# \$

100

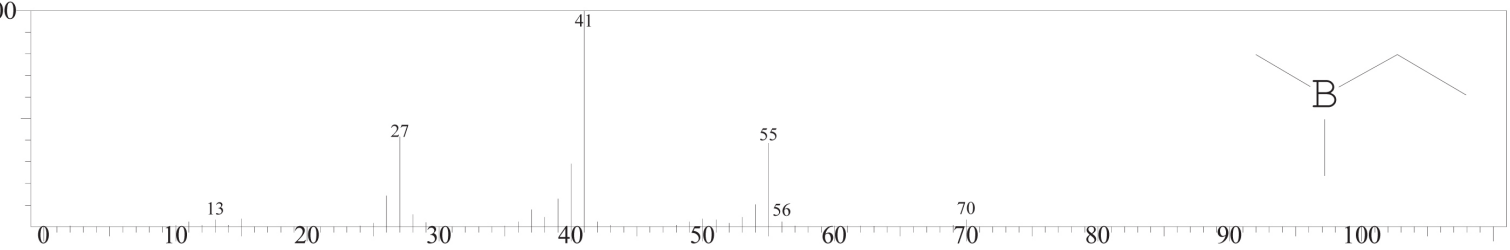

Hit\#:3 Entry:25178 Library:NIST08.LIB

SI:82 Formula:C8H10O4 CAS:0-00-0 MolWeight:170 RetIndex:1131

CompName:Oxalicacid, diallyl ester

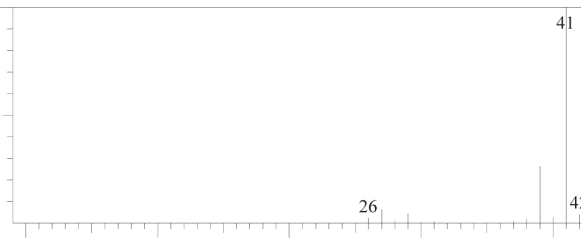

$0 \quad 10$

20

30

1

Hit\#:4 Entry:620 Library:NIST08.LIB

SI:82 Formula:C5H9N CAS:2769-64-4 MolWeight:83 RetIndex:0

CompName:Butane, 1-isocyano- \$ Butyl isocyanide \$ \$n-Butyl isocyanide \$ B Butylisonitrile \$ \$n-C4H9NC \$

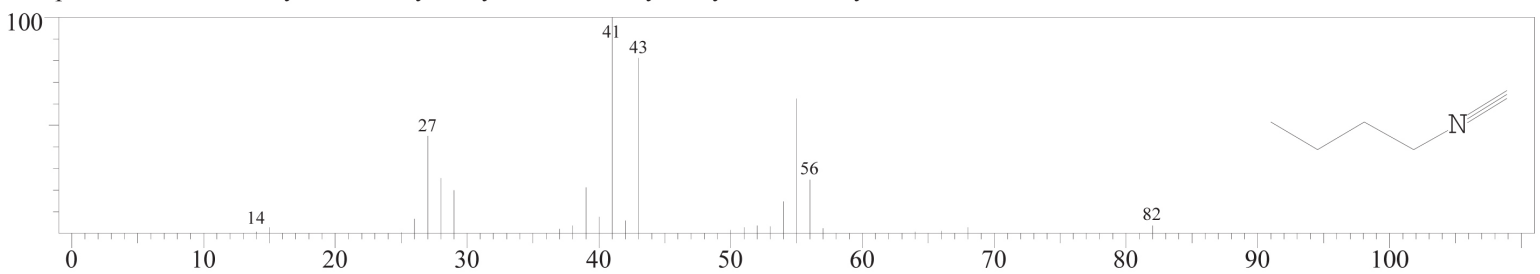

Hit\#:5 Entry:91 Library:NIST08.LIB

SI:82 Formula:C3H9B CAS:593-90-8 MolWeight:56 RetIndex:0

CompName:Borane, trimethyl- \$ Trimethylborane \$ Trimethylboron \$ $(\mathrm{CH} 3) 3 \mathrm{~B} \$ \$$

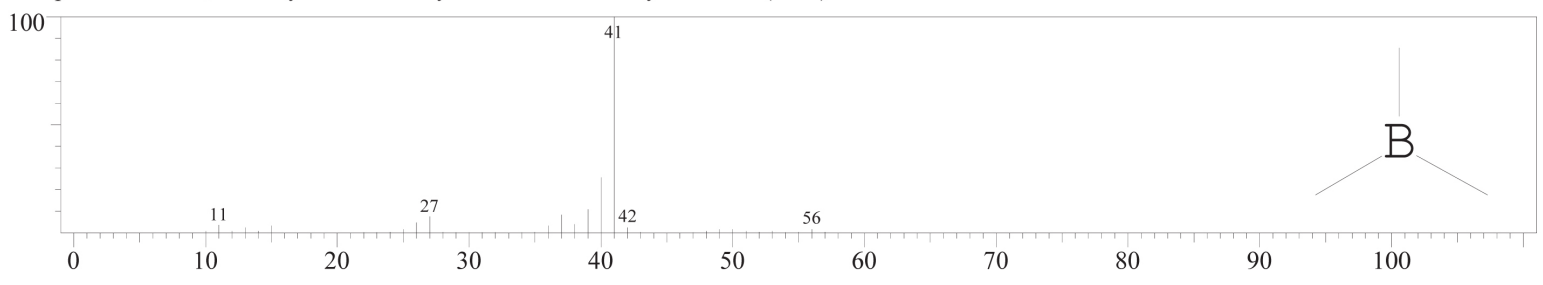


$<<$ Target $>>$

Line\#:2 R.Time:13.267(Scan\#:1353) MassPeaks:4

RawMode:Averaged 13.242-13.300(1350-1357)BasePeak:41.00(769)

BG Mode:13.250(1351) Group 1 - Event 1

100

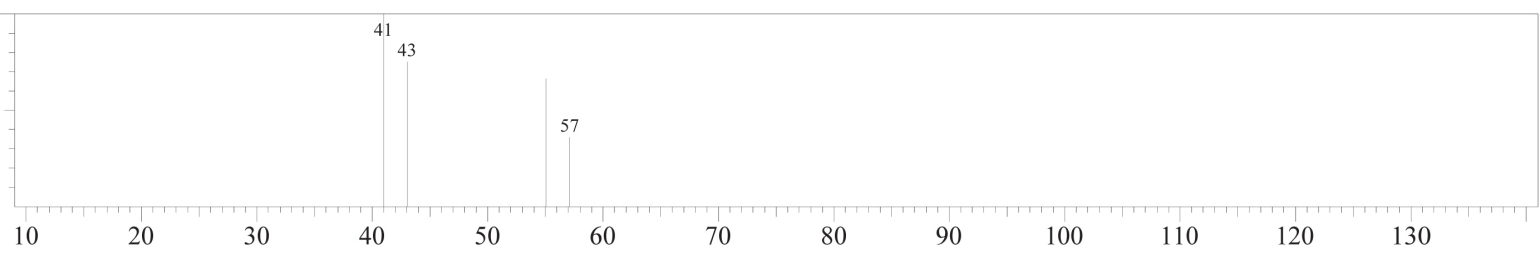

Hit\#:1 Entry:620 Library:NIST08.LIB

SI:85 Formula:C5H9N CAS:2769-64-4 MolWeight:83 RetIndex:0

CompName:Butane, 1-isocyano- \$ Butyl isocyanide \$ \$n-Butyl isocyanide \$ Butylisonitrile \$ \$n-C4H9NC \$

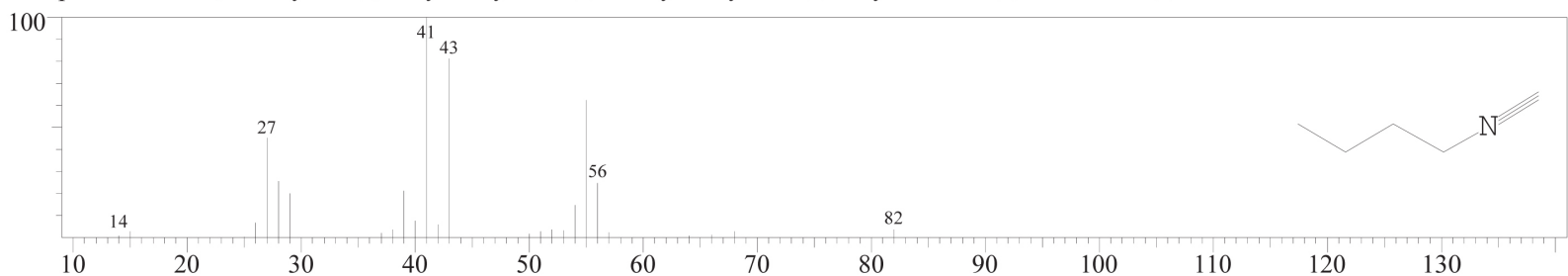

Hit\#:2 Entry:13866 Library:NIST08.LIB

SI:83 Formula:C5H9NO2S CAS:175137-61-8 MolWeight:147 RetIndex:1270

CompName:Propanesulfonylacetonitrile \$ (Propylsulfonyl)acetonitrile\#\$

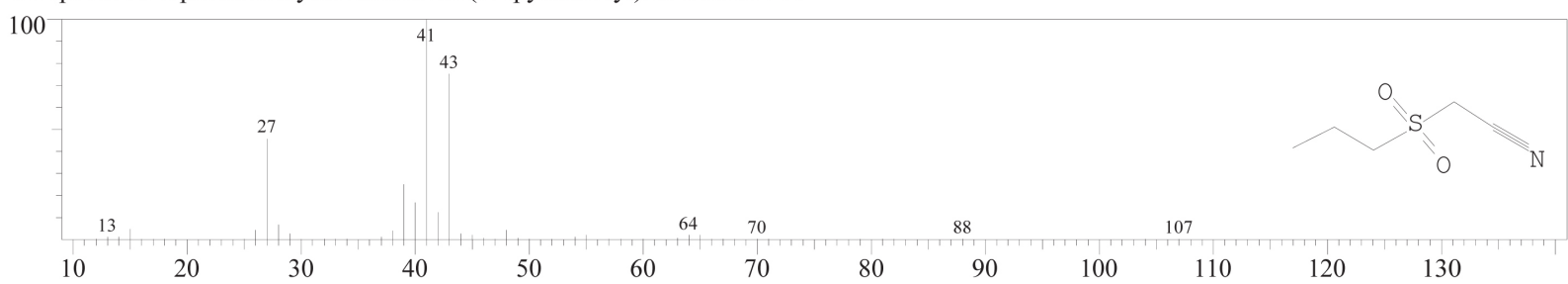

Hit\#:3 Entry:2375 Library:NIST08.LIB

SI:82 Formula:C4H9NO2 CAS:542-56-3 MolWeight:103 RetIndex:544

CompName:Isobutyl nitrite $\$ \$(\mathrm{CH} 3) 2 \mathrm{CHCH} 2 \mathrm{ONO} \$ \$$ Nitrous acid, 2-methylpropyl ester $\$ \$$ Nitrous acid, isobutyl ester $\$ \$$ IBN $\$ \$ \mathrm{NCI}-\mathrm{C} 61052 \$$

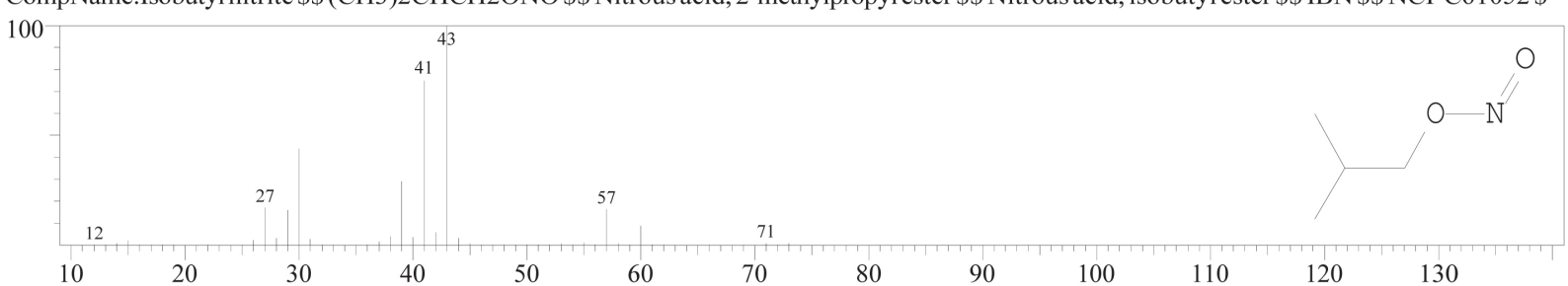

Hit\#:4 Entry:35307 Library:NIST08.LIB

SI:81 Formula:C9H16O4 CAS:0-00-0 MolWeight:188 RetIndex:1250

CompName:Oxalic acid, butyl propyl ester

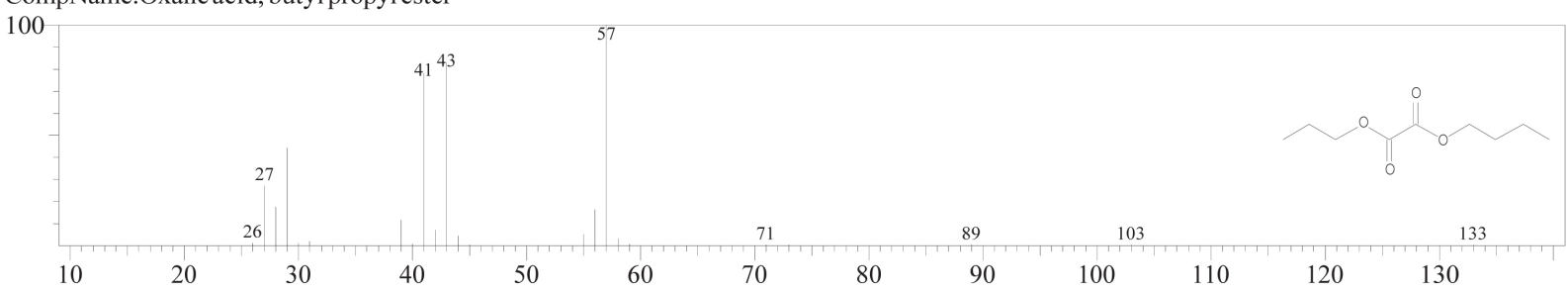

Hit\#:5 Entry:42629 Library:NIST08.LIB

SI:81 Formula:C10H16O4 CAS:0-00-0 MolWeight:200 RetIndex:1340

CompName:Oxalicacid, allyl pentyl ester

100

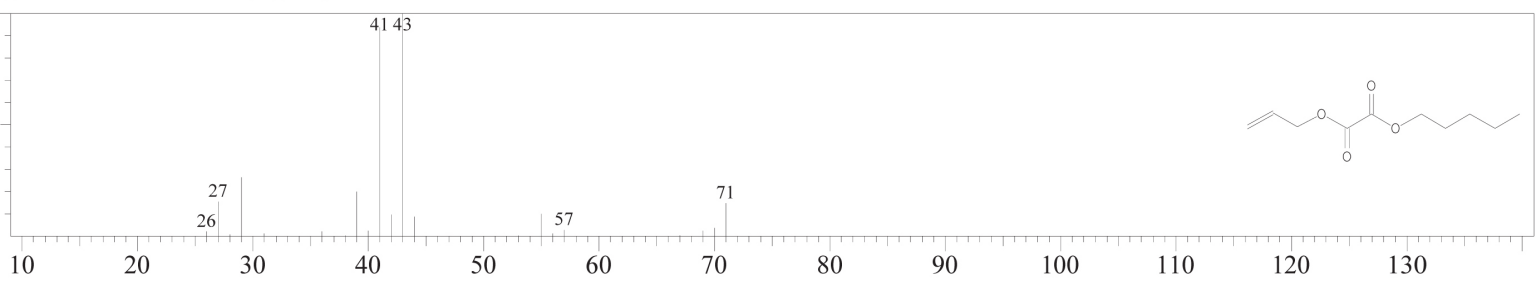


$<<$ Target $>>$

Line\#:3 R.Time:15.442(Scan\#:1614) MassPeaks:3

RawMode:Averaged 15.417-15.483(1611-1619)BasePeak:41.00(563)

BG Mode:15.483(1619) Group 1 - Event 1

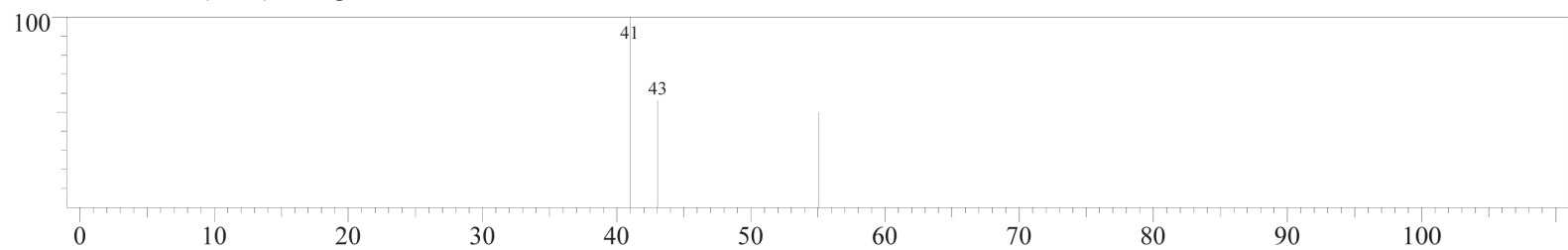

Hit\#:1 Entry:13866 Library:NIST08.LIB

SI:84 Formula:C5H9NO2S CAS:175137-61-8 MolWeight:147 RetIndex:1270

CompName:Propanesulfonylacetonitrile\$\$(Propylsulfonyl)acetonitrile\#\$\$

100

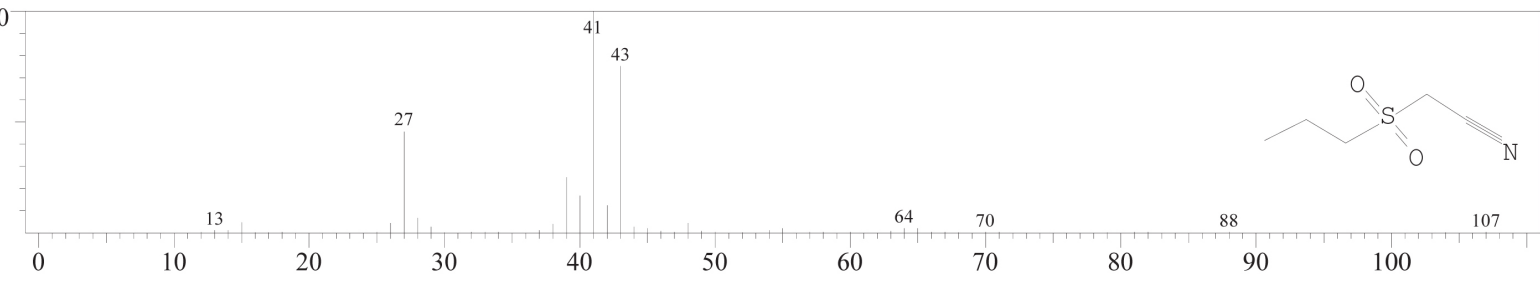

Hit\#:2 Entry:620 Library:NIST08.LIB

SI:83 Formula:C5H9N CAS:2769-64-4 MolWeight:83 RetIndex:0

CompName:Butane, 1-isocyano- \$ Butylisocyanide\$ \$n-Butyl isocyanide \$ Butylisonitrile \$ $\$$ n-C4H9NC \$

$$
100
$$

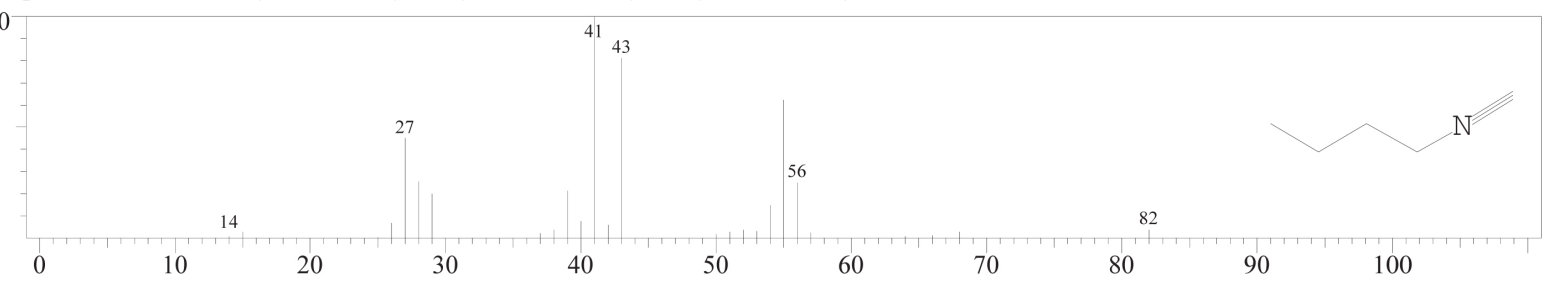

Hit\#:3 Entry:264 Library:NIST08.LIB

SI:82 Formula:C4H11B CAS:1113-22-0 MolWeight:70 RetIndex:0

CompName:Borane, ethyldimethyl- \$ \$ Dimethylethylborane \$ B Borine, ethyldimethyl-\$\$ Ethyl(dimethyl)borane\# \$

100

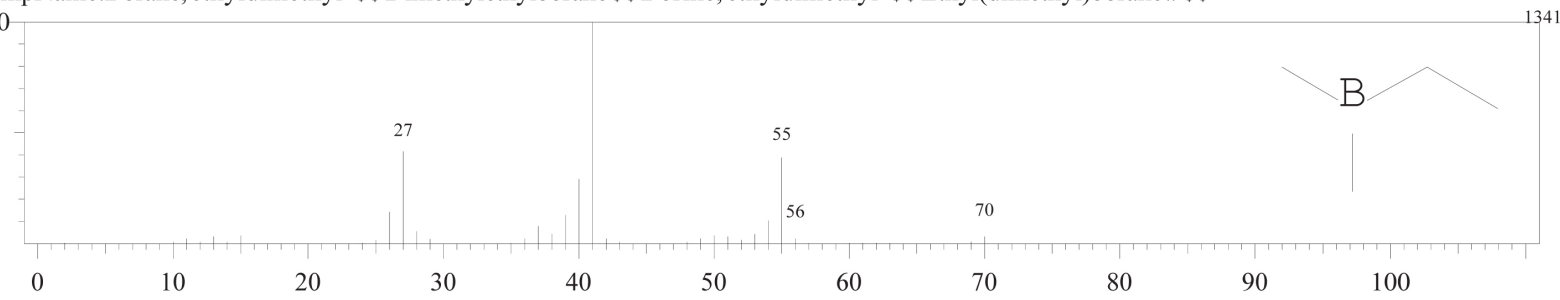

Hit\#:4 Entry:42629 Library:NIST08.LIB

SI:80 Formula:C10H16O4 CAS:0-00-0 MolWeight:200 RetIndex:1340

CompName:Oxalic acid, allyl pentyl ester

100

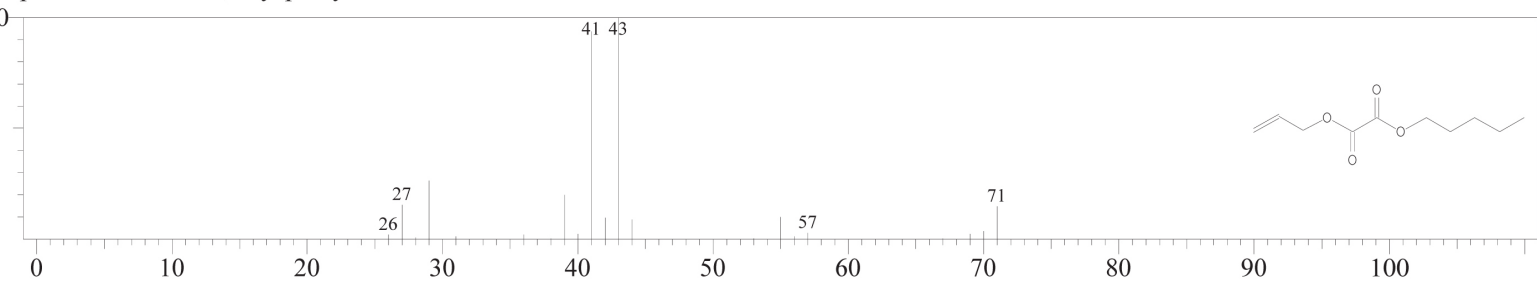

Hit\#:5 Entry:25178 Library:NIST08.LIB

SI:80 Formula:C8H10O4 CAS:0-00-0 MolWeight:170 RetIndex:1131

CompName:Oxalic acid, diallyl ester

100

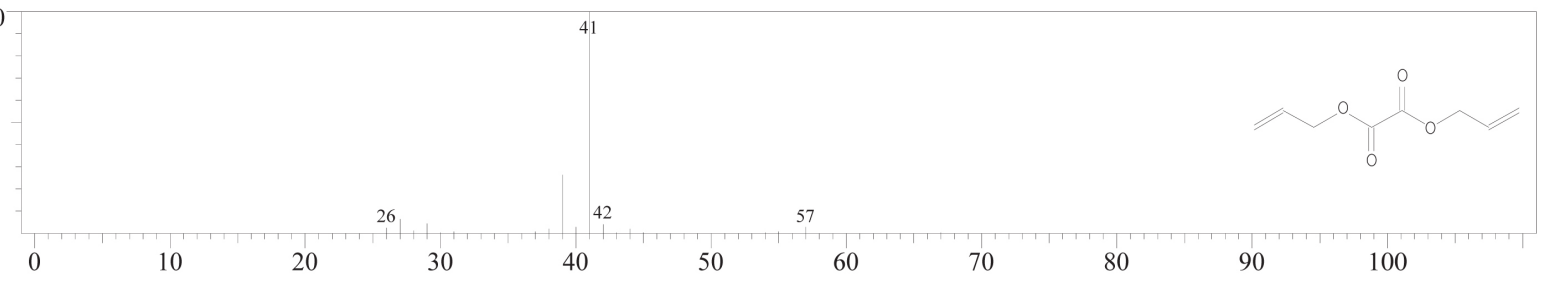


$<<$ Target $>>$

Line\#:4 R.Time:16.650(Scan\#:1759) MassPeaks:4 RawMode:Averaged 16.617-

16.683(1755-1763)BasePeak:41.00(669) BG Mode:16.692(1764) Group 1 - Event 1

100

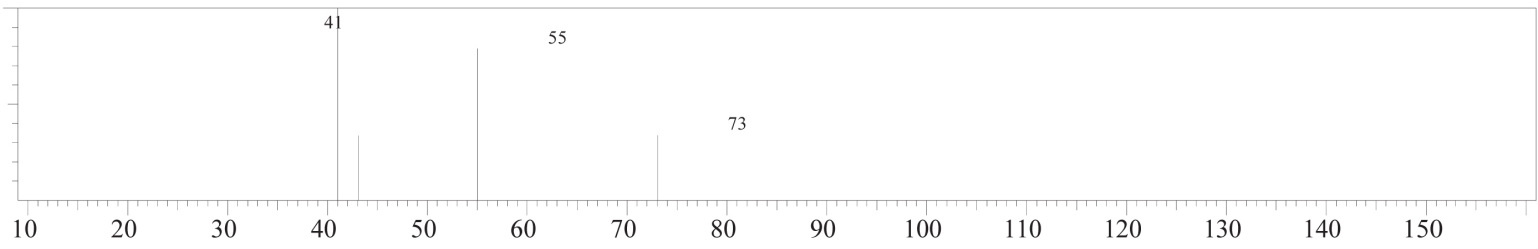

Hit\#:1 Entry:336 Library:NIST08.LIB

SI:77 Formula:C3H7NO CAS:6542-54-7 MolWeight:73 RetIndex:628 CompName:o-

Allylhydroxylamine

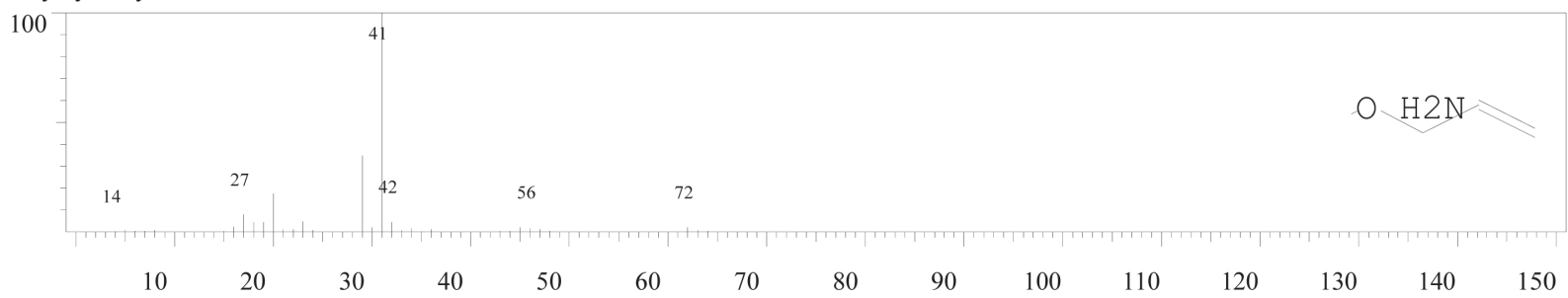

Hit\#:2 Entry:4003 Library:NIST08.LIB

SI:76 Formula:C6H10O2 CAS:689-12-3 MolWeight:114 RetIndex:711

CompName:Isopropyl acrylate \$ \$2-Propenoic acid, 1-methylethyl ester \$ \$ Acrylic acid, isopropyl ester \$ Isopropyl 2-propenoate \$ Isopropyl est

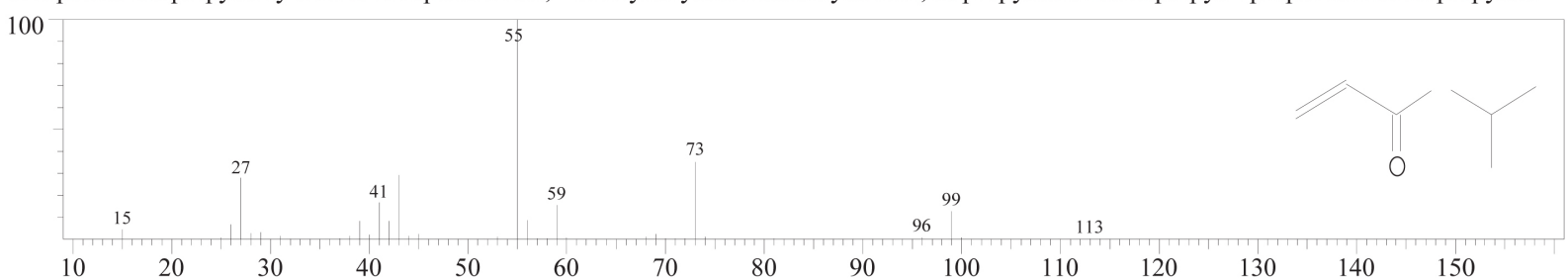

Hit\#:3 Entry:620 Library:NIST08.LIB

SI:76 Formula:C5H9N CAS:2769-64-4 MolWeight:83 RetIndex:0

CompName:Butane, 1-isocyano- \$ \$ Butylisocyanide \$ \$n-Butyl isocyanide \$ Butylisonitrile \$ \$n-C4H9NC \$

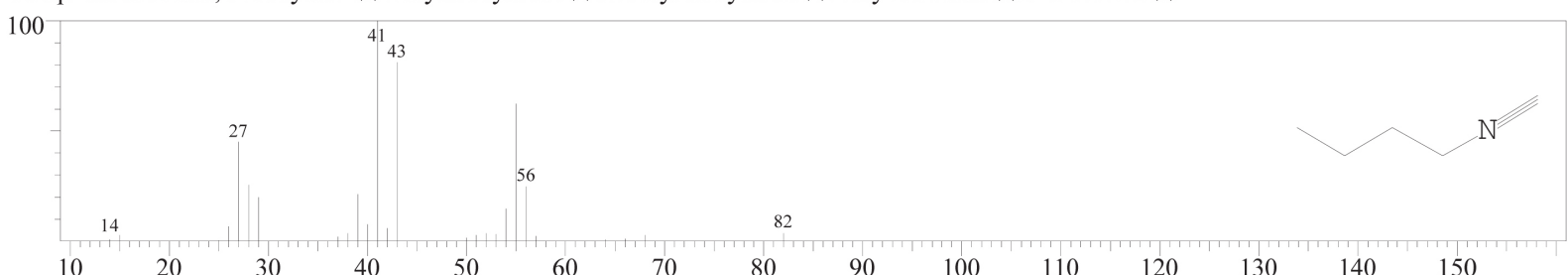

Hit\#:4 Entry:4670 Library:NIST08.LIB

SI:76 Formula:C7H16O CAS:589-55-9 MolWeight:116 RetIndex:879

CompName:4-Heptanol \$ \$ Dipropylcarbinol \$ $\$ \mathrm{CH} 3(\mathrm{CH} 2) 2 \mathrm{CHOH}(\mathrm{CH} 2) 2 \mathrm{CH} 3$ \$ di-n-Propylcarbinol \$ $\$$ n-Heptan-4-ol \$

100

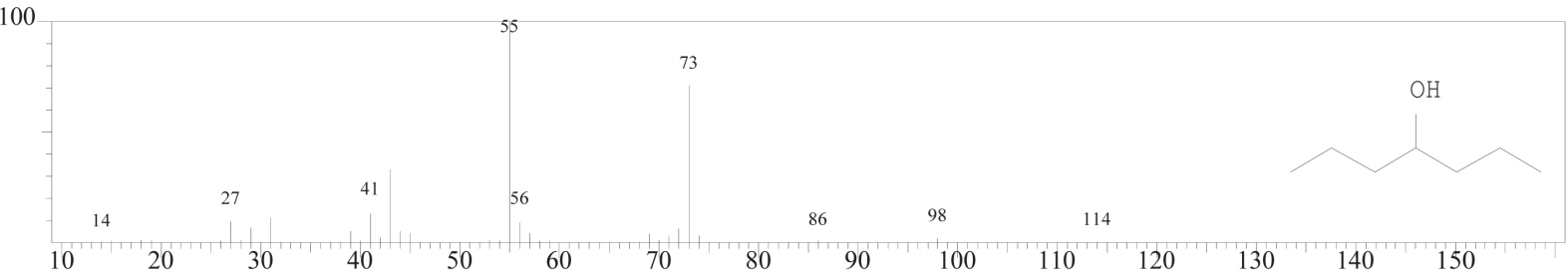

Hit\#:5 Entry:42363 Library:NIST08.LIB

SI:75 Formula:C4H9IO CAS:127201-28-9 MolWeight:200 RetIndex:1012

CompName:1-Butanol, 2-iodo- $\$$ 2-Iodo-1-butanol\#\$\$

100

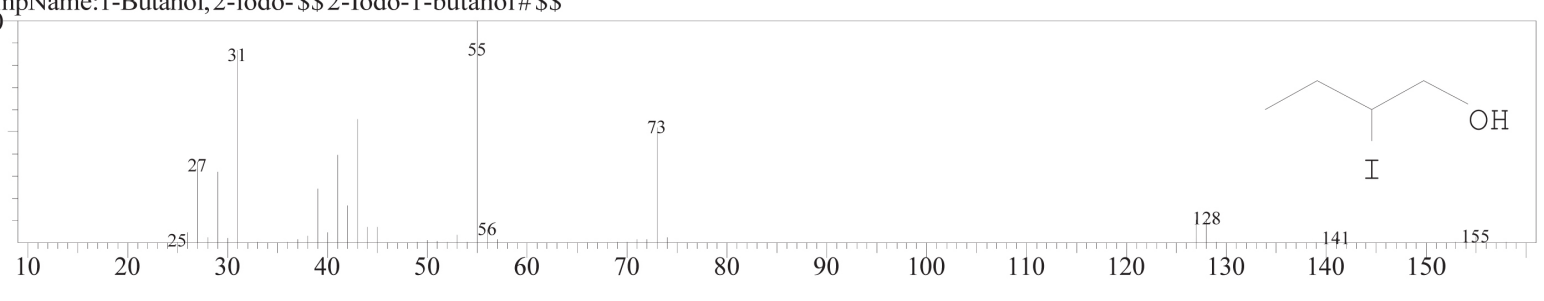


$<<$ Target $>>$

Line\#:5 R.Time:16.783(Scan\#:1775) MassPeaks:18

RawMode:Averaged 16.733-16.842(1769-1782)BasePeak:58.05(1950)

BG Mode:16.850(1783) Group 1 - Event 1

100

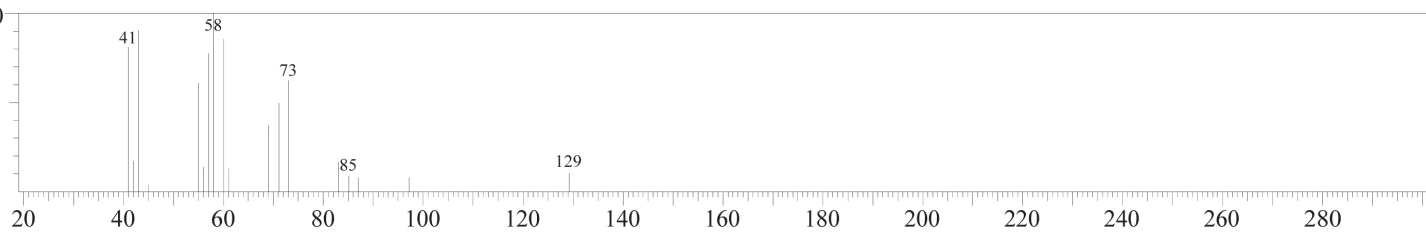

Hit\#:1 Entry:80732 Library:NIST08.LIB

SI:83 Formula:C16H32O2 CAS:57-10-3 MolWeight:256 RetIndex:1968

CompName:n-Hexadecanoic acid \$ \$ Hexadecanoic acid \$ \$n-Hexadecoic acid \$ Palmitic acid \$ Pentadecanecarboxylic acid \$ $1-$ Pentadecanecar 100

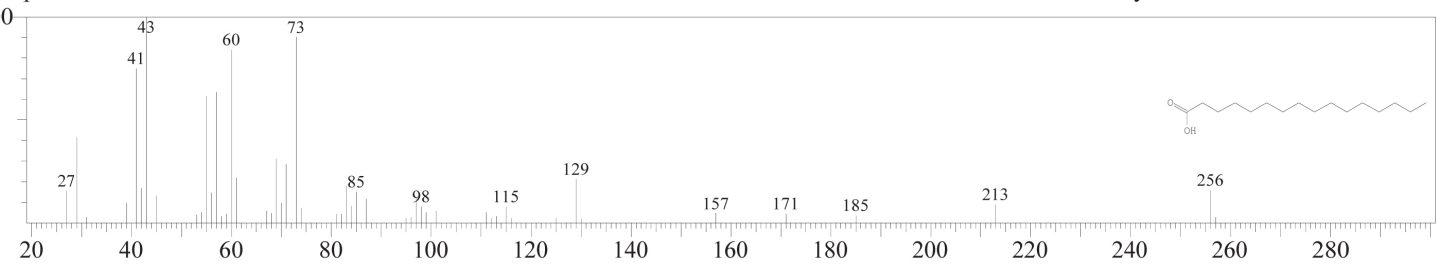

Hit\#:2 Entry:110794 Library:NIST08.LIB

SI:81 Formula:C19H38O2 CAS:646-30-0 MolWeight:298 RetIndex:2266

CompName:Nonadecanoicacid \$ \$n-Nonadecanoic acid \$\$

100

43

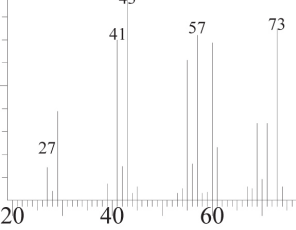

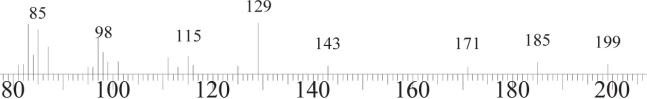

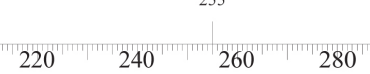

Hit\#:3 Entry:9419 Library:NIST08.LIB

SI:80 Formula:C6H13ClO CAS:74685-46-4 MolWeight:136 RetIndex:857

CompName:3-Pentanol, 2-chloro-4-methyl-, ( $\left.\mathrm{R}^{*}, \mathrm{R}^{*}\right)-(.+/-$.$) - \$\$ 3-Pentanol, 2-chloro-4-methyl-, (R*,R*)-(.+-.)- \$\$ 2-Chloro-4-methyl-3-pentanol \#$ 100

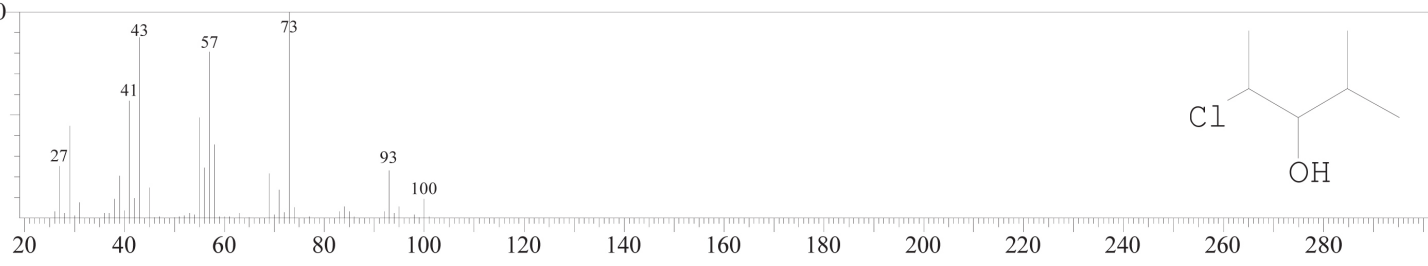

Hit\#:4 Entry:52033 Library:NIST08.LIB

SI:79 Formula:C13H26O2 CAS:638-53-9 MolWeight:214 RetIndex:1670

CompName:Tridecanoic acid \$ \$n-Tridecanoic acid \$ $\$$-Tridecoic acid \$ Tridecylic acid \$\$

$$
100
$$

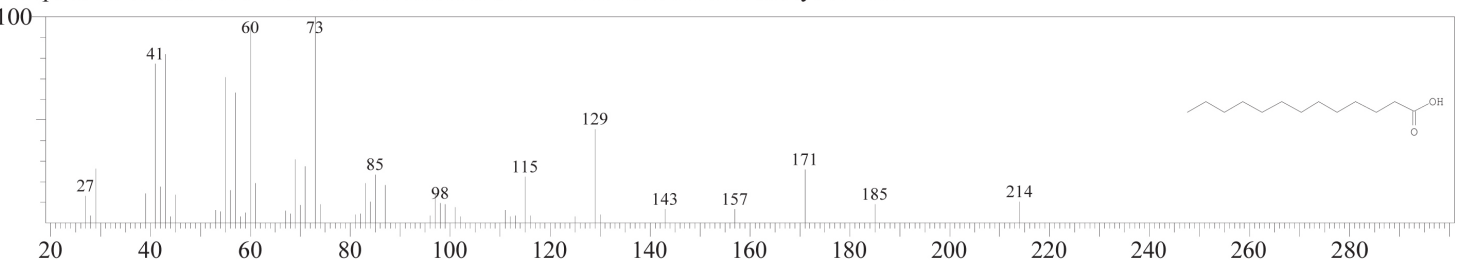

Hit\#:5 Entry:26672 Library:NIST08.LIB

SI:79 Formula:C10H20O2 CAS:334-48-5 MolWeight:172 RetIndex:1372

CompName:n-Decanoic acid \$ \$ Decanoic acid \$ \$n-Capric acid \$\$n-Decoic acid \$\$n-Decylic acid \$ Capric acid $\$ \$$ Caprinic acid $\$ \$ C$ Caprynic ac 100

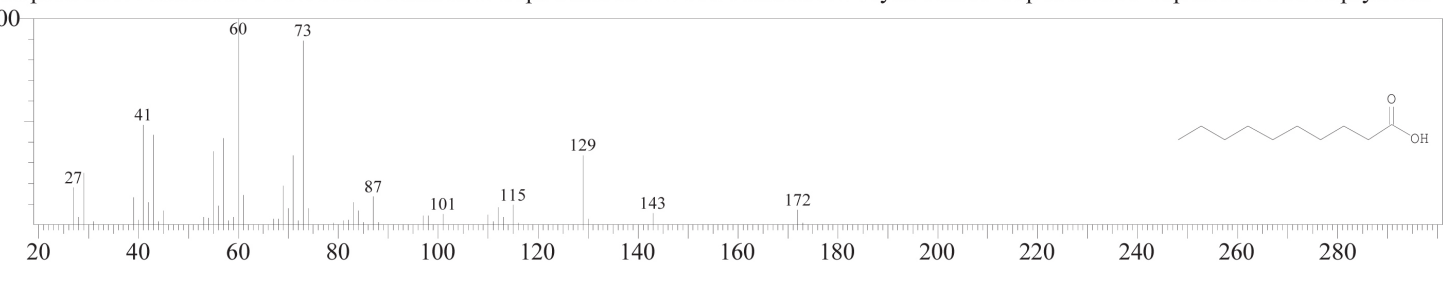


$<<$ Target $>>$

Line\#:6 R.Time:16.992(Scan\#:1800) MassPeaks:4

RawMode:Averaged 16.942-17.017(1794-1803)BasePeak:55.05(701)

BG Mode:17.008(1802) Group 1 - Event 1

100

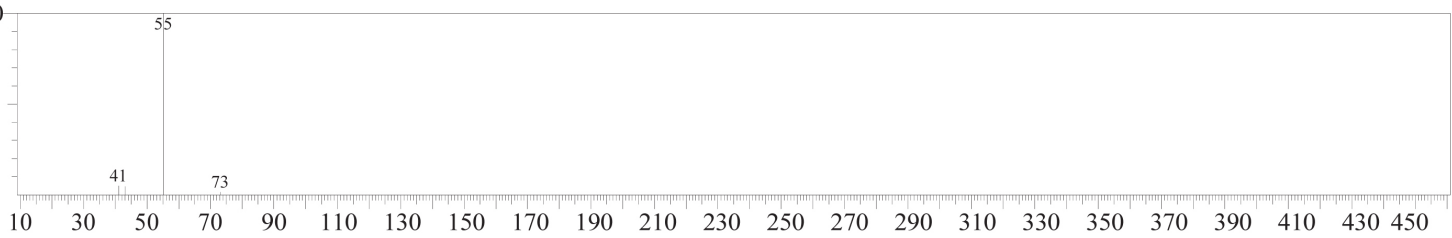

Hit\#:1 Entry:1568 Library:NIST08.LIB

SI:91 Formula:C5H6O2 CAS:2177-18-6 MolWeight:98 RetIndex:666

CompName:2-Propenoic acid, ethenyl ester \$ \$ Acrylic acid, vinyl ester \$ Vinyl acrylate \$

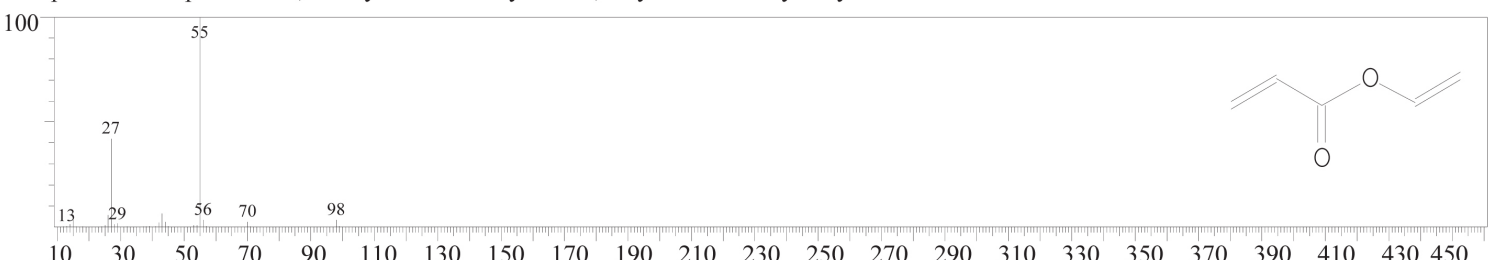

Hit\#:2 Entry:89 Library:NIST08.LIB

SI:91 Formula:C3H4O CAS:107-19-7 MolWeight:56 RetIndex:560

CompName:2-Propyn-1-ol \$ E Ethynyl carbinol \$ \$ Propargyl alcohol \$ Propynyl alcohol \$ 1-Hydroxy-2-propyne \$ 1-Propyn-3-ol \$ 2 -Propynol 100

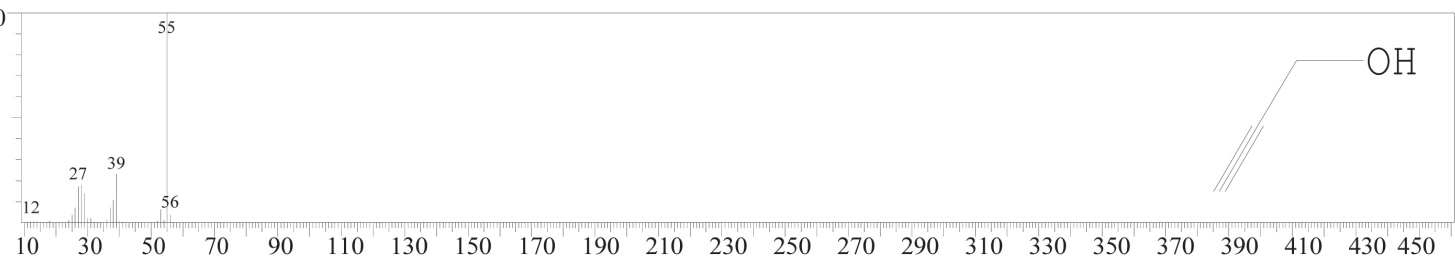

Hit\#:3 Entry:7026 Library:NIST08.LIB

SI:89 Formula:C6H8O3 CAS:106-90-1 MolWeight:128 RetIndex:865

CompName:2-Propenoic acid, oxiranylmethyl ester \$ \$ Acrylic acid, 2,3-epoxypropyl ester \$ Glycidyl acrylate \$ Glycidyl propenate \$ 2,3-Epoxy

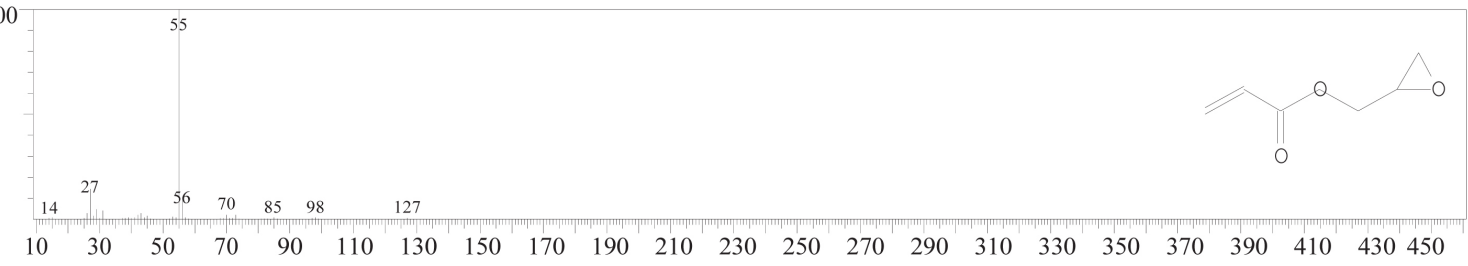

Hit\#:4 Entry:41447 Library:NIST08.LIB

SI:89 Formula:C10H14O4 CAS:0-00-0 MolWeight:198 RetIndex:1395

CompName:Oxalic acid, dicyclobutyl ester

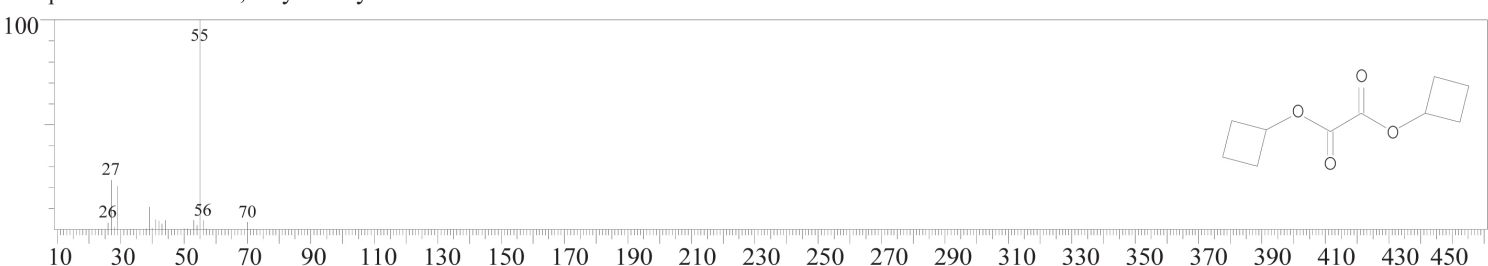

Hit\#:5 Entry:179454 Library:NIST08.LIB

SI:88 Formula:C11H5F15O2 CAS:307-98-2 MolWeight:454 RetIndex:274

CompName:2-Propenoic acid, 2,2,3,3,4,4,5,5,6,6,7,7,8,8,8-pentadecafluorooctyl ester $\$ \$ 2,2,3,3,4,4,5,5,6,6,7,7,8,8,8$-Pentadecafluorooctyl acrylate 100

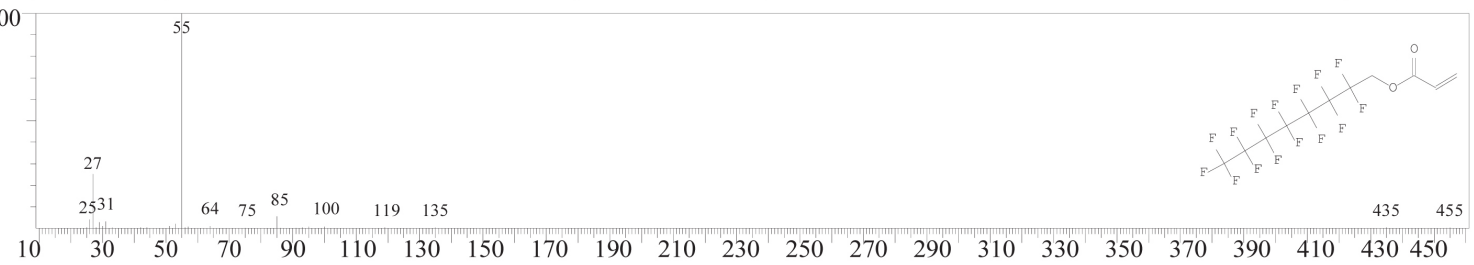


$<<$ Target $>>$

Line\#:8 R.Time:18.033(Scan\#:1925) MassPeaks:7

RawMode:Averaged 18.008-18.067(1922-1929)BasePeak:57.05(829)

BG Mode:18.083(1931) Group 1 - Event 1

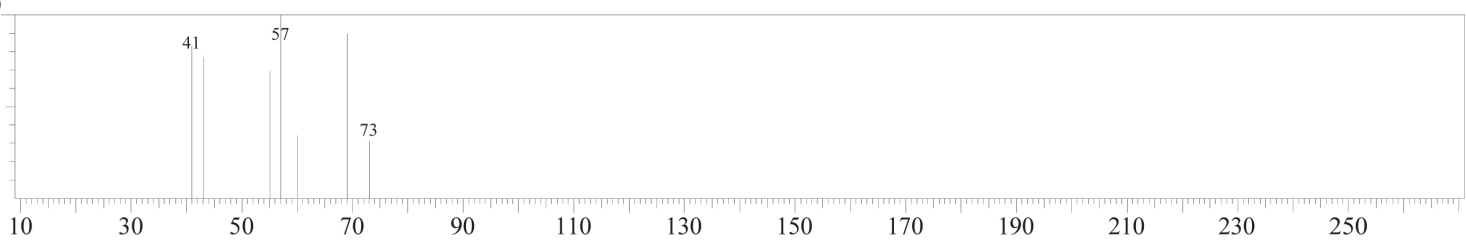

Hit\#:1 Entry:44024 Library:NIST08.LIB

SI:76 Formula:C12H26O2 CAS:13262-24-3 MolWeight:202 RetIndex:1109

CompName:1,1-Diisobutoxy-isobutane \$ \$1,1-Diisobutoxy-2-methylpropane\#\$\$

100

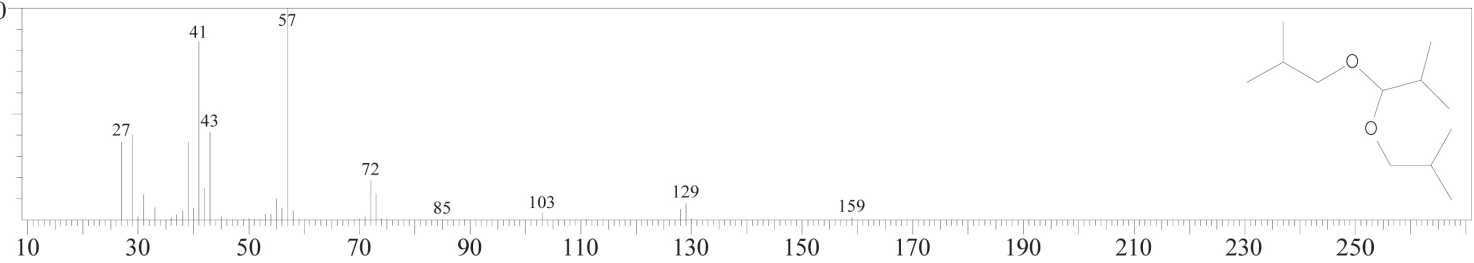

Hit\#:2 Entry:44023 Library:NIST08.LIB

SI:76 Formula:C12H26O2 CAS:13002-16-9 MolWeight:202 RetIndex:1174

CompName:1,1-Diisobutoxy-butane

100

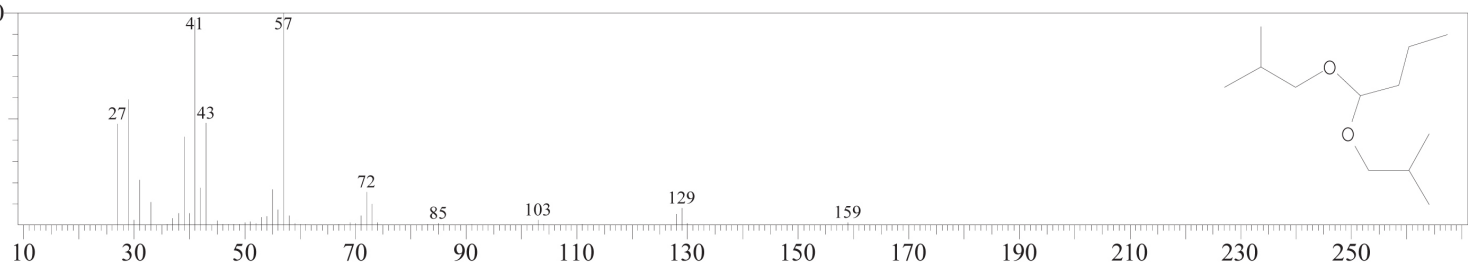

Hit\#:3 Entry:99958 Library:NIST08.LIB

SI:75 Formula:C9H11F7O2 CAS:0-00-0 MolWeight:284 RetIndex:555

CompName:Heptafluorobutyric acid, 2,2-dimethylpropyl ester

100

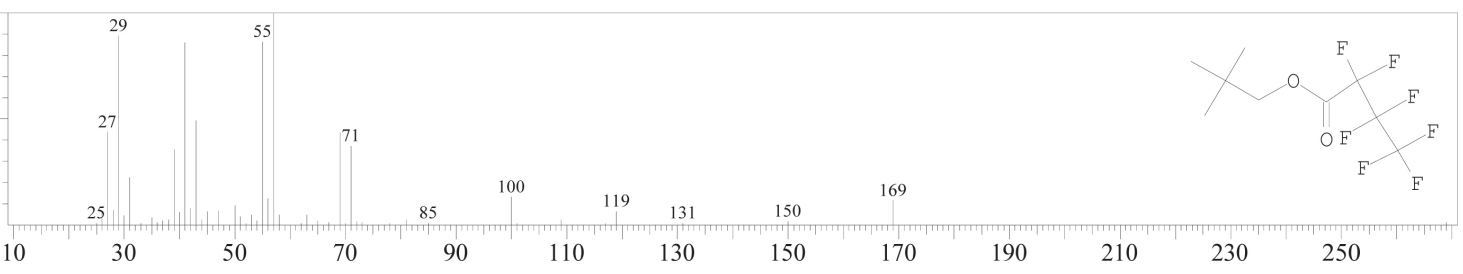

Hit\#:4 Entry:34345 Library:NIST08.LIB

SI:75 Formula:C10H18O3 CAS:25023-14-7 MolWeight:186 RetIndex:1217

CompName:t-Butyl cyclopentaneperoxycarboxylate \$\$ tert-Butyl cyclopentanecarboperoxoate \# \$\$

100

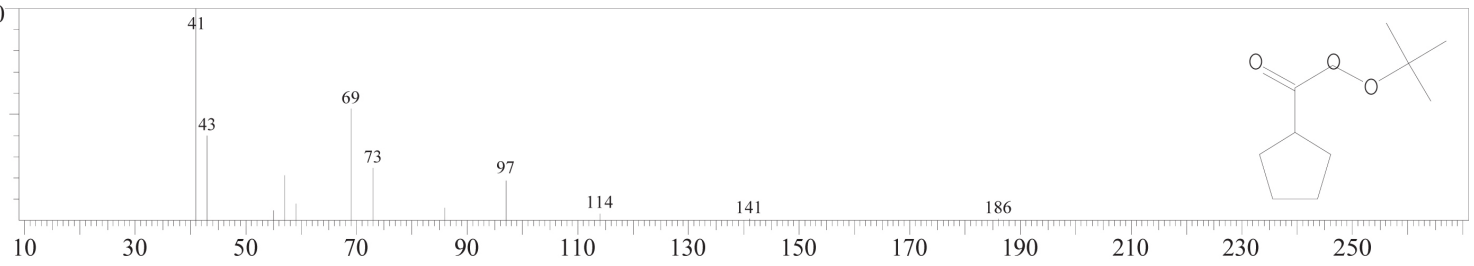

Hit\#:5 Entry:4738 Library:NIST08.LIB

SI:75 Formula:C5H11NO2 CAS:110-46-3 MolWeight:117 RetIndex:644

CompName:Isoamyl nitrite \$ Nitrous acid, 3-methylbutyl ester \$ Isopentyl alcohol, nitrite \$ \$ Aspiral \$ Isopentyl nitrite \$ Nitramyl \$ V aporole

100

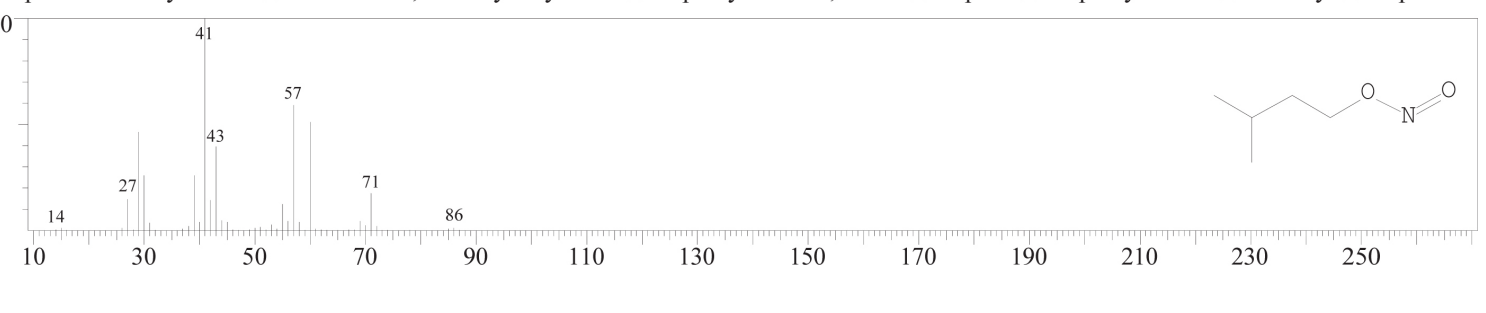

